\title{
A busca de uma nova agenda de pesquisa sobre os movimentos sociais e o confronto político: diálogos com Sidney Tarrow
}

[Comentários ao artigo de Sidney Tarrow]

Breno Bringel*

\section{A recepção das teorias norte-americanas sobre a ação coletiva e os movimentos sociais no Brasil}

\begin{abstract}
Como introdução aos meus comentários sobre a conferência de Sidney Tarrow gostaria de fazer uma apreciação inicial sobre a recepção das teorias norte-americanas sobre a ação coletiva e os movimentos sociais no Brasil. A publicação recente em português de $O$ Poder em Movimento (TARROW, 2009a) e o interesse despertado por esta primeira visita de Tarrow ao Brasil são mostras de uma crescente influência tanto da sua obra como do projeto coletivo "contentious politics" no país. No entanto, trata-se de um fenômeno relativamente novo, já que até recentemente a discussão sobre as teorias norte-americanas, neste campo de estudo, no Brasil esteve caracterizada por ser: a) indireta; b) tardia; c) parcial/limitada ${ }^{11}$.

Indireta por que a discussão, até recentemente, foi realizada principalmente a través do esforço analítico de alguns colegas bra-
\end{abstract}

Pesquisador honorífico do Departamento de Ciência Política III da Universidade Complutense de Madri. Endereço eletrônico: brenobringel@hotmail.com.

1 Este texto está baseado na minha intervenção como comentarista da conferência Global, Conventional and Warring Movements and the Suppression of Contention: themes in contentious politics research de Sidney Tarrow, pronunciada no dia 12 de Agosto de 2010 no I Seminário Internacional (III Seminário Nacional) “Movimentos Sociais, Participação e Democracia”, realizado na Universidade Federal de Santa Catarina. Agradeço a Comissão Organizadora do evento e, em particular a Ilse Scherer-Warren, Ligia Helena Hahn Lüchmann, Julian Borba e Carlos Sell pelo convite. Sou especialmente grato a Sidney Tarrow pelo diálogo, referências e vários comentários, virtuais e presenciais, sobre várias questões que aparecem no presente texto. 
sileiros, onde se destaca o já clássico trabalho de sistematização de Gohn (1997) que vêm servindo como um verdadeiro mapa teórico para os estudiosos dos movimentos sociais no Brasil, principalmente os mais jovens. Deste modo, a teoria da mobilização dos recursos, a noção de frames ou as estruturas de oportunidades políticas nunca foram totalmente desconhecidas, mas não chegaram ao Brasil via Doug McAdam, John McCarthy, David Snow ou o próprio Tarrow, entre muitos outros, mas sim via trabalhos como o de Maria da Glória Gohn. Por outro lado, outros autores que estudaram nos Estados Unidos ou mantiveram uma relação mais próxima com a academia daquele país trouxeram contribuições interessantes ao estudo da realidade brasileira a partir de um enfoque que dialoga com autores e correntes teóricas norte-americanas. Um bom exemplo na década de 1990 é o estudo de Sandoval (1994) que, muito influenciado por Charles Tilly, analisa as atividades grevistas no Brasil de 1945 a 1990 combinando uma descrição quantitativa com a análise histórica.

Tardia por que a recepção de obras como 0 Poder em Movimento, originalmente publicada em 1994, demorou quinze anos em chegar ao Brasil. Contudo, ainda que segue sendo um referente iniludível, chega num momento onde a discussão nacional, norteamericana e internacional vêm tomando novos rumos, o que explica que a terceira edição inglesa deste livro ${ }^{2}$, que será publicada durante o ano 2011, esteja sendo revisada ao ponto de encontrar discussões completamente novas sobre os processos e mecanismos de contestação. Isto deve ser problematizado no sentido de que a leitura de "O Poder em movimento" pelo público brasileiro deve ser realizada de forma paralela com textos mais recentes vinculados ao debate internacional atual, com o objetivo de que não ocorra uma "defasagem espaço-temporal" que impeça um engajamento e inserção sincrônica do debate brasileiro com a literatura produzida e discutida em outros lugares ${ }^{3}$. Neste sentido, são mais que bemvindas as traduções que vem aparecendo nos últimos anos em várias

2 A versão brasileira é uma tradução da segunda edição publicada em inglês em 1998.

3 Vide nesta direção o texto de Alonso (2009) que propõe uma atualização do debate teórico sobre os movimentos sociais incorporando elementos recentes da discussão norte-americana. 
revistas nacionais: em 2009 publica-se, por exemplo, um texto de Tarrow sobre ativismo transnacional na Revista Caderno CRH (TARROW, 2009b) e o artigo "Para mapear o confronto político" na Revista Lua Nova (MCADAM, TARROW \& TILLY, 2009). Em 2010 é publicado na Revista Brasileira de Ciência Política um texto de Tilly (2010) sobre movimentos sociais e política ${ }^{4}$. No primeiro caso, trata-se de um texto que contribui teoricamente ao importante debate contemporâneo sobre a ação coletiva transnacional, ao qual Tarrow já dedicou um importante livro (TARROW, 2005), ainda pouco discutido no Brasil. No segundo caso, o texto da Lua Nova representa o pontapé inicial do projeto coletivo "contentious politics", publicado originalmente em 1996 no número inaugural da revista internacional Mobilization. Finalmente, o texto de Tilly versa sobre uma reflexão recente do autor, na qual seguia apostando por sua peculiar análise histórica, mas já incorporando muitos dos elementos recentes da discussão norte-americana como a busca de mecanismos causais e relacionais e as "performances" (TILLY, 2008) como expressão coletiva.

Parcial/limitada já que se bem algumas obras seminais demoraram a chegar e certos debates contemporâneos começam a circular, textos fundamentais nunca foram nem traduzidos nem seriamente discutidos. Penso aqui em concreto na "magnum opus" From Mobilization to Revolution de Tilly (1978) sem a qual é impensável pensar o posterior desenvolvimento do estudo das ações coletivas no cenário norte-americano. Noções como o "interesse" para a mobilização e as "oportunidades" para a produção de ações coletivas (de repressão à facilitação, de maiores oportunidades a diferentes tipos de ameaças), assim como outros importantes componentes para o estudo da ação coletiva como a "organização", a "mobilização" e a "ação coletiva” per se (que, de acordo com Tilly, poderia ser entendida através das mudanças no "repertório" de ação coletiva, de várias

4 A publicação desses textos coincide com a aparição recente no Brasil de vários dossiês temáticos sobre "Ações coletivas e Movimentos Sociais", como o organizado por Ilse Scherer-Warren (Revista "Sociedade e Estado", 2006), por mim de forma conjunta com Maria Victória Espiñeira (Revista "Caderno CRH", 2008), por Brasilio Sallum Jr. (Revista "Lua Nova, 2009), por Marisa von Bülow e Rebecca Abers ("Revista Brasileira de Ciência Política”, 2010) e por Carlos Gadea (Revista "Ciências Sociais UNISINOS", 2010). 
formas de violência coletiva e dentro das turbulências de revoluções e rebeliões) devem muito a esta obra de Tilly, que conseguiu que o estudo da ação coletiva ganhasse um foco próprio tanto dentro da história como da sociologia.

Estas reflexões preliminares sobre a recepção das teorias norte-americanas no Brasil nos levam a uma pergunta obrigatória: quais as razões para essa recepção indireta, tardia e parcial/limitada? Não há uma única explicação, mas sim uma confluência de fatores que devem ser pensados em conjunto. Em uma conversa com Tarrow, ele me sugeriu três pistas que são interessantes para explorar esta questão: a primeira delas, o anti-imperialismo latino-americano; a segunda, o profundo estruturalismo na tradição do pensamento social regional; a terceira, a influência de Alain Touraine e colaboradores a través das teorias dos novos movimentos sociais.

No que se refere ao anti-imperialismo trata-se, de fato, de um elemento de grande peso desde finais do século XIX tanto na vida política latino-americana, de forma geral, como entre os movimentos sociais da região, de maneira mais específica. A história do século XX na América Latina está fortemente marcada por complexas relações entre os governos/projetos estadunidenses e a intelligentsia políticomilitar da região e várias intervenções, de diferente tipo, baseadas na defesa da "segurança hemisférica" no período da guerra-fria (AYERBE, 2002). O golpe militar de 1964 no Brasil, por exemplo, contou com um apoio ativo do Departamento de Estado dos Estados Unidos e inclusive depois da queda do muro de Berlim, e a pesar do declínio da hegemonia dos Estados Unidos, o sentimento social de rejeição continua sendo forte devido aos novos intentos de influência do país na região, como pôde ser comprovado na Campanha brasileira contra o Acordo de Livre Comércio das Américas (ALCA) ou nos protestos contra a visita de Bush ao Brasil em 2007.

Se cruzarmos a questão do anti-imperialismo com a do estruturalismo no pensamento regional podemos encontrar outros elementos relacionados importantes para responder nossa pergunta. Uma questão chave é o forte engajamento dos acadêmicos latinoamericanos com a vida político-social desde a institucionalização das ciências sociais na década de 1930, mas principalmente nas décadas de 1960 e 1970 (momento em que se institucionaliza o debate 
acadêmico sobre os movimentos sociais). Isto tem, ao menos, duas implicações diretas: por um lado, enquanto nos anos 1960 Marcus Olson e os adeptos da escolha racional, criticando o funcionalismo das "teorias dos grupos", travam nos Estados Unidos uma discussão sobre os interesses individuais e a ação coletiva, na América Latina as abordagens sobre os movimentos sociais apostam pelo coletivo e negam a possibilidade de uma dissociação entre o âmbito científico e político, buscando contribuições teórico-metodológicas de co-produção de conhecimento orientado para a ação (FALS-BORBA, 1961; FREIRE, 1967; STAVENHAGEN, 1971). Por outro lado, para além do que González Casanova (1963) denominou como "colonialismo interno" no terreno econômico, político, social e cultural, sempre houve uma tensão constituinte na sociologia latino-americana referente à construção de análises próprios desvinculados do eurocentrismo e, de forma geral, de um "ocidentocentrismo".

As teorias estruturalistas e da dependência surgem neste contexto como uma tentativa de realizar uma teorização baseada nas especificidades da posição da América Latina, partindo da crítica aos paradigmas hegemônicos sobre o desenvolvimento. Seus contornos específicos nem sempre foram bem interpretados no mundo anglosaxão e certamente tiveram muitas limitações e tentativas originais de atualização (KAY, 2009), porém constituem um dos importantes patrimônios da teoria social regional, cujas categorias ou conceitos associados normalmente são marginais nas análises externas sobre a ação coletiva e os movimentos sociais. Sua aplicação na América Latina incidiu mais no debate sobre a "mudança social" em termos gerais que na análise específica sobre os atores sociais, o que levou posteriormente à tensão constante entre o foco na estrutura ou na ação.

Inclusive Alain Touraine, quem realmente teve uma grande influência nos estudos sobre os movimentos sociais na América Latina nos anos 1970 e 1980 (talvez inclusive mais que na Europa), chegou a escrever sobre a problemática da existência de uma sociologia própria na América Latina, considerando aspectos como a modernização, a integração nacional e a dependência (TOURAINE, 1989a). A discussão sobre a influência da sociologia da ação de Alain Touraine no debate sobre os movimentos sociais no Brasil, 
principalmente a partir de suas contribuições sobre modernidade na América Latina, sujeito social e democracia, já foi motivo de ampla reflexão (GOHN, 2008; GADEA \& SCHERER-WARREN, 2005). Também podemos lembrar a presença física do autor no debate acadêmico brasileiro, chileno e de outros países e a construção de reflexões pensadas especificamente para a realidade latino-americana (TOURAINE, 1989b) como fatores relevantes para sua incidência.

Tudo isto, assim como a comparação entre os processos de transição política à democracia no Sul da Europa e na América Latina (tema que gerou um importante número de trabalhos comparados), contribuiu para que o debate sobre os "novos movimentos sociais" fosse mais forte no Brasil que os debates existentes nos anos 1980 nos Estados Unidos ${ }^{5}$. A própria polarização do momento, traduzida muitas vezes em enfrentamento, entre os "novos movimentos sociais" e o estudo dos "processos políticos" certamente tenha repercutido na maior recepção do primeiro. Por outro lado, a maior ênfase no jogo político-institucional não era muito atrativa em um momento onde a autonomia era uma palavra-chave.

No entanto, a pesar desta importante influência européia no debate brasileiro sobre os movimentos sociais, é importante dizer que a discussão sobre os novos movimentos sociais na América do Sul acabaram adquirindo rasgos próprios com interpretações sobre o "basismo", a cultura política ou as "novidades específicas" da realidade brasileira e regional que contrastavam com a européia (SCHERER-WARREN \& KRISCHKE, 1987; SADER, 1988). Isto nos leva a pensar em uma tendência mais ampla, onde a recepção do pensamento social e político na América Latina nunca foi acrítico nem aceitou facilmente os moldes externos. Pelo contrário, "foi em geral uma recepção criativa, pois ao considerar que a América Latina apresentava problemas específicos, foi adaptando e não seguindo de forma mimética as fontes européias ou norte-americanas. Uma consequiência desta recepção criativa é a configuração de corren-

5 Poderíamos adicionar também que o peso da presença do argentino Ernesto Laclau, bastante lido no Brasil, nos primeiros debates europeus sobre os movimentos sociais, como o organizado em Amsterdam por Slater (1985), também seja um fator adicional para a influência desta corrente no país. 
tes de pensamento próprias a partir da combinação de rasgos que, nos países de origem, encontravam-se separados" (FRANZÉ, 2008, p.281). É assim, por exemplo, como o pensamento nacional-popular conformou-se como um dos aportes mais originais da região às idéias políticas ocidentais ao fundir elementos como o nacionalismo e o socialismo que, em outros contextos, eram vistos como heterogêneos e inclusive como excludentes. O nome do peruano José Carlos Mariátegui também é uma referência obrigatória já que, a pesar de uma forte influência do marxismo ocidental e de autores como Gramsci, Lukács e Walter Benjamin, tratou de articular um socialismo de caráter "indo-americano" e um “comunismo inca” (MARIÁTEGUI, 2005).

Em suma, uma última forma alternativa de interpretar esta questão é extrapolar uma idéia bastante desenvolvida pelo próprio Tarrow - as "dinâmicas de difusão"6 - e propor que a difusão de idéias e práticas sociais ${ }^{7}$ sempre foi, em temos gerais, mais relacional e fluída entre o Brasil e alguns países da Europa que entre o Brasil e os Estados Unidos.

6 A noção de "difusão" tem uma longa trajetória no estudo dos movimentos sociais nos Estados Unidos e é utilizada por Tarrow $(2005 ; 2010)$ como aqueles elementos e mecanismos que permitem entender como discursos, demandas, experiências e repertórios de protesto se disseminam entre diferentes lugares, em alguns casos muitos distantes uns dos outros. Existiriam três formas principais de difusão: relacional (a emulação de novas formas de contestação por parte de atores com relações prévias de confiança, intimidade ou comunicação regular com aqueles que iniciaram ditas formas), não-relacional (a emulação de novas formas de contestação por parte daqueles atores que aprendem estas a partir de meios impessoais como os meios) e mediada (a emulação de novas formas de contestação por parte de atores sem laços prévios com aqueles que iniciaram estas formas e a partir da intervenção de terceiros que mantém uma relação de confiança tanto com os iniciadores como com os que a adotam).

7 Não podemos esquecer que, para além do âmbito das idéias, a formação das lutas sociais brasileiras de finais do século XIX e inícios do século XX, por exemplo, teve uma importante influência do anarquismo e das experienciais trazidas à região por migrantes italianos e espanhóis e também uma incidência, ainda que mais reduzida, da Segunda Internacional (Bruckman e Dos Santos, 2008). Esta troca de experiências de resistências sociais continuou sendo mais fluída entre a América Latina e a Europa e, dentro das redes transnacionais de movimentos sociais contemporâneos, encontramos um crescente vínculo entre organizações de ambas as regiões como é o caso da Rede "Enlazando Alternativas", construída como uma experiência bi-regional de movimentos sociais (BRINGEL e CAIRO, 2010; ECHART, 2008). 


\section{Sobre a reconfiguração dos estudos sobre a ação coletiva e os movimentos sociais}

No entanto, a partir da década de 1990 , o contexto de profundas transformações no cenário global leva ao questionamento de muitas certezas e paradigmas. As mudanças no plano social, político, econômico e cultural se refletem na extensão do "Consenso de Washington" e do discurso globalizante, mas também em novas articulações e expressões da política transformadora e da "cultura do protesto", o que incita, consequientemente, novas interpretações. Deste modo, é importante localizar tanto a conferência de Tarrow como o I Seminário Internacional (III Seminário Nacional) "Movimentos Sociais, Participação e Democracia" dentro de um momento crucial ao qual nos enfrentamos tanto para a articulação de uma política de esquerda transformadora em tempos de crises e convulsões globais como para a construção de uma agenda de estudo renovada sobre as ações coletivas e os movimentos sociais.

Como dizíamos antes, a construção desta nova agenda de pesquisa no cenário internacional começa a ser articulada principalmente a partir da década de 1990 , momento no qual o debate brasileiro sobre os movimentos sociais padece de certa apatia após duas décadas de intensa discussão sobre os movimentos sociais nos contextos de luta contra a ditadura militar e pela democratização. Além disso, pode-se dizer que a renovação internacional do debate tem uma perspectiva bidirecional, que olha tanto para trás como para frente. Para trás, por que se as "teorias clássicas" que apareceram a partir da década de 1960 com a institucionalização acadêmica do debate se enfrentavam diretamente contra o marxismo e o funcionalismo, no caso das teorizações emergentes na atualidade observa-se que também há um profundo diálogo crítico com as teorias antes hegemônicas (desde a teoria da mobilização de recursos passando pelo paradigma do processo político e pelo paradigma cultural-identitário, habitualmente identificado com as teorias dos novos movimentos sociais). E para frente, pois se busca problematizar novos fenômenos como o ativismo transnacional contemporâneo -dentro do que Tarrow (2005) considera um "internacionalismo complexo", o papel multidimensional das tecnologias 
de comunicação, os novos tipos de mobilização étnicas, culturais e novas redes de contestação.

É importante destacar que uma das características mais importantes da reconfiguração do campo de estudos sobre a ação coletiva e os movimentos sociais é a presença de um maior pluralismo, manifestado no que podemos denominar como um "incremento de interações" de diferente tipo: disciplinares, espaciais e teóricas. No campo disciplinar, a hegemonia inicial da sociologia combinada com outras disciplinas mais periféricas, porém sempre presentes, como a história, a ciência política ou a psicologia (KLANDERMANS e ROGGEBAND, 2007) convive com uma crescente influência de categorias e ferramentas conceituais críticas de disciplinas como a geografia, outrora marginada. Por outro lado, observa-se uma crescente internacionalização e transnacionalização (ainda muito desigual) da comunidade acadêmica e uma ampliação das lentes analíticas a experiências de lugares do Sul Global, dentro de uma reconfiguração mais ampla da geopolítica do conhecimento (MIGNOLO, 2003). Finalmente, a construção de uma maior interação teórica é uma tendência que se manifesta em propostas marcadas pelo sincretismo conceitual onde é difícil falar de "escolas" (norteamericana, européia, etc.) mais ou menos delimitadas, ou pelo menos diretamente enfrentadas, como antes.

Nas últimas duas décadas produziram-se vários "giros teóricos", frente às escolas "clássicas" no estudo das ações coletivas e dos movimentos sociais, que levam a um questionamento de questões teóricas, metodológicas, ontológicas e epistemológicas. Não posso me deter aqui nas várias e complexas mudanças ocorridas, mas gostaria de ressaltar que a busca desta nova agenda de pesquisa, no cenário internacional, deve-se em grande parte ao impulso do projeto "contentious politics" 8 , do qual Tarrow fez parte desde o

8 Aproveitamos para fazer uma importante precisão. As traduções mais habituais do termo "contentious politics" no Brasil tem sido "política contenciosa", "litígio coletivo" e, mais recentemente, "confronto político". Em espanhol, o termo tem sido traduzido como "política contenciosa" ou como "contienda política". Cremos que a tradução mais satisfatória seria a de "confronto político" ou inclusive "política contestatória", assim como termos contend/ contention como "contestar ou confrontar" / "contestação ou confronto", já 
início, com colegas como McAdam e Tilly. Dito projeto busca fugir do estruturalismo prévio (TARROW, 2006) a partir de mecanismos mais relacionais de análise, ampliando as lentes analíticas para além dos movimentos sociais (captando novas formas de expressão da contestação ou do confronto político), incluindo temas como nacionalismo, a democratização, a violência política e inclusive o terrorismo. Desse modo, estes autores buscam criar um marco suficientemente amplo que permita busca processos e mecanismos causais similares que se repetem dentro de uma grande variedade de lutas, mas que produzem diferentes resultados agregados de acordo com as condições iniciais, as combinações e as sequiências em que ocorrem (MCADAM, TARROW \& TILLY, 2001). Para isto, reconhecem que o estudo sistemático de uma grande variedade de "eventos de protesto" na Europa e na América do Norte levou a que o grupo visse a importância de considerar as interações estratégicas e a cultura. Oportunidades, ameaças, estruturas de mobilização e repertórios não desaparecem totalmente, mas adquirem novos sentidos a partir da ênfase nos processos e mecanismos.

O caráter amplo da proposta, unido a uma crescente busca de análises mais dinâmicas e a força dos "estudos transnacionais" que observam de forma sistemática as interações, fluxos e relações em diferentes realidades no mundo, fez com que na última década o enfoque do "confronto político" tenha ganhado uma enorme centralidade não só nos Estados Unidos, mas também na Europa e em outras partes do Sul Global. A coleção Cambridge Studies in Contentious Politics da Cambridge University Press editou nos últimos anos excelentes livros dedicados à interpretação da realidade latinoamericana, como os de Yashar (2005) sobre a emergência dos movimentos indígenas, o de Auyero (2007) sobre a violência coletiva na Argentina em Dezembro de 2001 e, mais recentemente, o da colega brasileira Von Bülow (2010) sobre redes transnacionais na luta contra o livre comércio. Também dentro do Brasil vêm crescendo o número

que, em nossa opinião, estas acepções preservam melhor o sentido de oposição, conflito e reivindicação intrínseco a este projeto coletivo de pesquisa, em detrimento do sentido mais jurídico de "política contenciosa" (que poderia resultar confuso) ou do sentido demasiado generalista de "litígio coletivo" ou "contenda política" (como disputa entre vários). 
de análises que utilizam o marco do confronto político. Talvez isso se deva, a grandes rasgos, ao entendimento deste projeto de que nem toda atividade política implica o conflito e o enfrentamento, propondo uma diferenciação entre um cenário "contido" e outro "transgressor". Esta é uma forte tendência no Brasil na mudança de século, onde se observa uma consolidação de novos atores sociais mais institucionalizados e a reconfiguração de movimentos sociais mais conflituosos em uma dinâmica de mobilização que combina tanto a cooperação como o conflito (GOHN, 2010).

Por outro lado, a influência da linha de pesquisa sobre o confronto político se vê parcialmente limitada tanto o Brasil, como na América Latina de forma geral, pela renovação de duas tendências: por um lado, a insistência em interpretações que tenham como foco os movimentos sociais e os sujeitos sociais (e não a ação coletiva de forma mais ampla ou outros atores) e, por outro lado, a busca de novas teorizações que tenham como eixo a busca de análises, pensados especificamente para a realidade latino-americana, que renovem a tradição crítica da teoria social regional.

No primeiro caso, podemos destacar todos aqueles estudos orientados à discussão renovada sobre a autonomia e a criação de contrapoderes (ou antipoderes), muito influenciados pela experiência do zapatismo e de outras experiências como as do MST brasileiro, dos piqueteros argentinos ou a guerra da água e do gás na Bolívia (ZIBECHI, 2006, 2007). Também podem ser incluídos aqui todos os estudos recentes que tem como eixo a dimensão espacial dos movimentos sociais e a importância do território e das identidades na construção de novas territorialidades (PORTOGONÇALVES, 2001) ou inclusive aqueles que seguem falando das especificidades dos "movimentos populares" ou da renovação da matriz nacional-popular (GARCÍA-LINERA, 2006) a partir de novas formas de auto-representação da "sociedade plebéia".

Estes eixos teóricos influenciados pelas intensas lutas sociais recentes na região estão acompanhados por uma segunda tendência mais ampla de renovação do pensamento regional que assume um caráter epistemológico. Para além do legado da desigualdade e as injustiças sociais profundas do colonialismo e do imperialismo (algo que já havia sido assinalado pelos teóricos da dependência), projetos 
latino-americanos "descoloniais" como o impulsionado pelo grupo "modernidade/colonialidade" denunciam um legado epistemológico do eurocentrismo que impede compreender o mundo a partir do próprio mundo em que vivemos e os saberes que lhe são próprios. Ainda que estas propostas de descolonização do saber e do poder tenham um caráter muito normativo, reivindicam e buscam construir uma nova teoria política para os movimentos populares (DUSSEL, 2010). Ao mesmo tempo, abrem pistas tanto para que possam ser desenvolvidas propostas mais específicas sobre uma descolonização das teorias dos movimentos sociais (BRINGEL, 2010) e são complementadas por reflexões sociológicas mais amplas sobre o horizonte de possibilidades emergente na região (DOMINGUES, 2009).

\section{A "sociedade em movimento": movimentos globais, convencionais (contidos) e beligerantes}

Não creio que a construção de um marco teórico renovado sobre as ações coletivas e os movimentos sociais na América Latina, que considere as lutas atuais, as especificidades regionais e incorpore o debate epistemológico anteriormente mencionado, esteja divorciado da inclusão e diálogo crítico com alguns aportes do projeto "confronto político". Por isso, a discussão com Tarrow é mais que bem-vinda e se até aqui meu objetivo foi, em primeiro lugar, refletir sobre a recepção das teorias norte-americanas sobre o estudo das ações coletivas no Brasil e, em segundo lugar, assinalar alguns rasgos da renovação contemporânea do debate sobre os movimentos sociais e o confronto político, a partir de agora farei alguns breves comentários relacionados diretamente ao texto de Tarrow. O objetivo não é fazer uma análise detalhada e exaustiva, retomando cada uma de suas idéias mais interessantes (algo que cada leitor pode fazer extraindo suas próprias conclusões de acordo com seus interesses específicos), mas sim dialogar com o autor em questões tratadas no texto que considero fundamentais para a renovação da agenda de estudo sobre os movimentos sociais e o confronto político e, conseqüientemente, para o entendimento das dinâmicas contemporâneas da contestação social e política. 


\subsection{Movimentos globais}

Tarrow retoma a expressão "sociedade em movimento" proposta em um livro editado no final dos anos 1990 (MEYER \& TARROW, 1998) e três de seus possíveis significados (movimentos globais, movimentos convencionais e movimentos beligerantes) para estruturar sua fala. Uma primeira idéia chave que Tarrow contesta e que me parece relevante resgatar é a visão de que a globalização relegou os conflitos políticos de nível domésticos (locais, nacionais) a um espectro secundário. Tampouco estou de acordo com isto. Os conflitos locais e nacionais seguem sendo muito relevantes como nos mostra Tarrow e o Estado-nação continua forte não só porque ainda consiste em um importante referente "real" e "mental" para os atores sociais, mas também porque detém o monopólio legítimo da violência, algo fundamental na luta política. Para mim a questão chave aqui reside em pensar a espacialidade da política contestatória, no sentido de acompanhar as múltiplas escalas, redes e dinâmicas de confronto. Só assim seremos capazes de observar que não há uma dicotomia entre o local e o global, que interagem continuamente, e que as escalas de ação dos movimentos sociais são contingentes e construídas socialmente.

Também concordo com Tarrow em que a globalização, ainda que seja um fenômeno crucial que leva a importantes mudanças, tem escasso poder explicativo para entender as dinâmicas do ativismo transnacional contemporâneo. Sua aposta em analisar as interações entre demandantes e seus objetos de demanda é mais interessante que atribuir à globalização ou ao neoliberalismo a lógica da ação coletiva, pois centra numa esfera "meso" onde trata aspectos macro e micro, mas sem dar um protagonismo a um ou outro nível de análise. Esta é uma importante contribuição para ir além das respostas habituais em muitos estudos recentes na América Latina que tem como foco mais a existência de um "inimigo" que o desenvolvimento sistemático de elementos que considerem como funcionam determinadas redes, coalizões, etc.

Outra questão importante relativa aos movimentos globais está relacionada à sua dimensão temporal: há certa insistência da maioria dos autores em considerar os anos 1990 como o marco 
inicial de uma série de protestos antiglobalização e de caráter transnacional. Em seu texto, Tarrow utiliza como referência uma periodização que desenvolvemos em texto recente (BRINGEL \& ECHART, 2010a), onde chamamos a atenção para um primeiro ciclo de protestos contra instituições financeiras internacionais já nos anos 1980. Neste sentido, ainda que seja certo que é na década de 1990 quando se intensificam as dinâmicas transnacionais do ativismo contemporâneo e quando surgem muitas redes e eventos, é importante acompanhar a trajetória histórica desses processos que na maioria dos casos vem de antes. É o que estamos fazendo em uma pesquisa em andamento sobre a internacionalização do MST e as dinâmicas transnacionais do ativismo rural contemporâneo, onde em vez de centrarmos o foco no surgimento da Coordenadora Latinoamericana de Organizações do Campo (CLOC) e da Via Campesina nos anos 1990, como vem sendo habitual, encontramos e analisamos importantes antecedentes na década de 1970 e 1980, entre os que podemos destacar a política do exílio de líderes camponeses.

Finalmente, Tarrow menciona brevemente como perfil dos ativistas transnacionais o estrato dos "cosmopolitas enraizados". Para Tarrow (2005, p.29; 2009b, p.152), o cosmopolita enraizado "mobiliza oportunidades e recursos domésticos e internacionais em ordem a conseguir determinadas demandas e avanços em nome de atores externos, em contra de opositores externos ou a favor de objetivos comuns com aliados transnacionais". Os ativistas transnacionais que se encaixam dentro do perfil proposto por Tarrow estariam, por tanto, enraizados em contextos nacionais específicos, mas imersos em atividades políticas de contestação que lhes insere em redes transnacionais de contatos e ações coletivas de diferente tipo. Como adiantamos em Bringel (2010), a excelente proposta de Tarrow é fértil para pensar o perfil de ativistas transnacionais, mas talvez possa ser complementada por um segundo estrato mais residual, porém também relevante. Pensemos naquele militante que não se encontra enraizado em um contexto nacional específico (e/ ou não pertencente a uma organização ou movimento social territorializado), mas que tem várias referências que lhe impede ter um marco territorializado de militância, assim como umas raízes muito marcadas ou definidas. Trata-se de um perfil emergente de militantes 
identificados em alguma medida com alguns movimentos sociais conformados por migrantes e, em menor grau, com o movimento antiglobalização (que não é sinônimo do Fórum Social Mundial), e que potencialmente poderiam construir seu âmbito de atuação política sem passar necessariamente pelo filtro do Estado-nação. A desterritorialização constante de muitos grupos, organizações e movimentos sociais supõe um processo de reterritorialização, no qual os atores sociais reformulam seus referentes, visões e marcos simbólicos e discursivos. Neste caso, o processo ocorre entre diferentes lugares, dentro ou não do Estado-nação.

Os movimentos migratórios supõem assim um importante desafio para os movimentos sociais e o confronto político, tanto no que se referem às novas articulações militantes de "comunidades migrantes" (por exemplo, o associativismo dos senegaleses na Espanha e na França, os mexicanos nos Estados Unidos ou as experiências de protesto de refugiados sudaneses no Egito), suas interações e solidariedades com os movimentos sociais do lugar de origem e destino (um exemplo são as campanhas de solidariedade de ativistas locais contra a criminalização dos migrantes "sem papéis"), mas também, num sentido mais amplo, pela reconfiguração e incidência do processo migratório, independente da sua escala, na reconfiguração das subjetividades, representações e vínculos de pertencimento dos ativistas. As migrações e a diáspora são fatores determinantes na conformação deste perfil de militante, que talvez possa complementar o proposto por Tarrow, e que normalmente tem incorporado à sua própria biografia pessoal e familiar uma considerável história de narrativas migrantes. Poder-se-ia falar assim de um ativista diaspórico com uma militância política marcada pela dispersão, que se produz, inclusive de forma simultânea, em ao menos dois lugares e que ainda que mantenha, em alguns casos como o africano, uma memória privilegiada sobre o lugar de origem e um território compartilhado, não está necessariamente pautada pela territorialidade do Estado-nação ou de uma região particular do mundo, mas por um projeto político e social específico imbuído em várias territorialidades e em múltiplas espacialidades. No imaginário destes ativistas diaspóricos, e na construção de sua "identidade diaspórica", estes projetos normalmente estão enquadrados na 
práxis de movimentos sociais transformadores, atos quotidianos de resistências ou práticas contestatórias que contribuem a gerar um imaginário alternativo sobre seu referente de conexão ou origem.

\subsection{Movimentos contidos}

A tendência à institucionalização da ação coletiva em vários lugares e o debate sobre a "rotinização do protesto" é outro dos eixos analíticos trazidos por Tarrow. Trata-se de tema clássico e bastante conhecido pelo público brasileiro nas últimas duas décadas. Neste ponto, talvez uma das contribuições mais sugestivas e provocadoras de Tarrow seja a de que as relações entre movimentos sociais e partidos são uma constante e que em vez de enfatizar a ausência de autonomia dos movimentos é melhor examinar os mecanismos particulares que conectam partidos e movimentos. Penso que ambas as coisas não são excludentes e operam como esferas complementares de articulação da vida social e política democrática contemporânea. Em Bringel e Echart (2008, p.465-469) propúnhamos analisar a relação entre movimentos sociais e democracia face à questão da autonomia e da institucionalidade a partir da dialética entre o âmbito do instituído e o âmbito do instituinte. No primeiro caso os mecanismos que conectam partidos e movimentos sociais são fundamentais e um dos focos de estudo pode ser o impacto da atuação dos movimentos nas "democracias realmente existentes", por exemplo, a través da ampliação do pluralismo informativo ou a inserção de novos temas nas agendas políticas, a incidência nas políticas públicas, etc. No segundo caso, o eixo fundamental constitui-se no possível potencial de criação de novas experiências democráticas nos espaços do movimento, para além do instituído, ainda que tencionando de alguma maneira com ele. Deste modo, se no primeiro caso a análise da conexão entre partidos e movimentos é crucial, no segundo a questão da autonomia é uma das chaves para pensar a democracia não só como demanda, mas como criação social.

Por outro lado, a experiência recente latino-americana obriga a geração de análises mais refinadas que superem a relação entre movimentos e partidos no seu sentido clássico. Os casos do Paraguai e da Bolívia, por exemplo, demonstram a criação de "plataformas eleitorais" 
da esquerda social como o Tekojoja e o Movimento Ao Socialismo (MAS), respectivamente, que necessitam ser pensadas de uma forma diferenciada à dos partidos de esquerda tradicionais na região.

Finalmente, se ligamos o ponto anterior sobre os movimentos globais com este, talvez também possamos falar de certa "rotinização do protesto" internacional dos atores sociais. É interessante observar que Tarrow destaca a diferença entre os modelos de advocacy, mais institucionalizados, e outras formas de transnacionalização mais direta e rupturista. Com o fim de um ciclo de protestos muito ativo no inicio do século na Europa e nos Estados Unidos, a tendência parece ser de predomínio do modelo mais institucionalizado, aonde a participação na cena internacional vem acontecendo mais "por convite" que "por irrupção" (ECHART, 2008).

\subsection{Movimentos beligerantes e novos mecanismos de criminalização do protesto}

No entanto, Tarrow lembra habilmente que esta proliferação de formas pouco rupturistas vem convivendo crescentemente com a emergência de movimentos beligerantes que empregam a violência como parte regular de seu repertório de contestação. Como pensar a re-emergência de movimentos de extrema-direita na Europa? Como interpretar a difusão global de movimentos violentos e sectários? O que dizer das redes terroristas? Concordo que estes são desafios importantes para os quais contamos com pouca bagagem analítica. Talvez no Brasil muitos possam pensar que o tema é de interesse exclusivo do Norte e uma obsessão dos Estados Unidos e da Europa. Porém, o tema da violência está fortemente presente nos repertórios de contestação latino-americanos e inclusive o tema do terrorismo vem estendendo-se com força e captando novas bases de operações em novos países no Sul Global, como no caso da África.

Isto nos leva à parte final do texto de Tarrow, onde nos traz um tema tão importante como escassamente debatido nos meios acadêmicos: os novos mecanismos a través dos quais os Estados e as forças policiais vem respondendo frente a este padrão híbrido de movimentos contidos e beligerantes. A repressão física nunca foi o único mecanismo de contenção das lutas sociais, mas na atu- 
alidade parecem emergir formatos mais refinados e complexos de controle dos protestos. Gostaria de destacar uma frase de Tarrow que é extremamente relevante: "estamos acostumados a observar como os Estados autoritários controlam o protesto, porém neste novo século a grande questão é como este tipo de controle também vem se estendendo no marco de Estados democrático-liberais". Certamente o 11-S e a luta contra o terrorismo foi um ponto de inflexão neste sentido. As mudanças nas práticas policiais não afetam somente os casos de terrorismo (cuja definição não está isenta de tensões), mas acabam afetando a maioria dos protestos mais radicalizados. No caso da luta contra a ETA no estado espanhol pude observar nos últimos anos como no cenário posterior aos atentados de Nova York e de Madri houve um incremento da criminalização sobre a esquerda mais rupturista e uma "estratégia adaptativa" de outros atores sociais.

O caso da Lei Patriótica exposto por Tarrow para os Estados Unidos é muito claro e podemos estender, sem muitas dificuldades, suas observações à América Latina e à Europa, onde dentro da construção de uma "região fortaleza" abrem-se as fronteiras para o capital, fecham-se para os migrantes e controlam-se de forma crescente os passos dos militantes. Um exemplo recente é a provação no dia 26 de Abril de 2010 pelo Conselho Europeu de Assuntos Gerais do Documento 8570/10. Este texto prevê que a União Européia observará "processos de radicalização", a través da vigilância de "agentes", que contribuem à radicalização de outras pessoas e que mantém "atitudes radicais". Incluem-se no mesmo pacote a "posturas de extrema esquerda ou direita, nacionalistas, religiosas ou antiglobalização". Num registro mais próximo vemos também como muitos movimentos sociais colombianos tem sido assediados e acusados como parte de redes terroristas. Até no Brasil as forças conservadoras se sintonizaram com o cenário global e não duvidaram em acusar o MST como organização terrorista.

O principal paradoxo é o seguinte: ao mesmo tempo em que governos locais e instituições internacionais clamam crescentemente pela "participação da sociedade civil", respondem com repressão e criminalização aos movimentos sociais mais conflituosos e aquelas expressões mais radicais de protesto. Deste modo, um determinado 
tipo de participação política é bem-vindo (aquela que se encaixa dentro de um marco sistêmico e mais reformista, e que inclusive pode contribuir a legitimar certas ações governamentais), enquanto todas aquelas que supõem algum tipo de ameaça ou simplesmente uma crítica lúcida são criminalizadas. Neste contexto, multiplicam-se as dificuldades enfrentadas pelos protestos e movimentos sociais mais reivindicativos face às novas políticas de controle social. Ao mesmo tempo, isto leva à emergência de formas não convencionais de ativismo, como destacou Tarrow, e cabe a nós definir bem os termos do debate: o que entendemos por violência, quais são as relações entre violência política e protesto social, o que é o terrorismo etc.

Enfim, devemos seguir de perto os passos do projeto contentious politics, pois nos aproxima a uma inovadora agenda de pesquisa para entender a contestação política a partir de importantes avanços teóricos e metodológicos. Tarrow menciona que um dos motivos para a revitalização deste projeto responde também a um giro epistemológico das posturas estruturalistas anteriores e a busca de mecanismos mais relacionais. No entanto, tenho a sensação de que o giro é de caráter mais ontológico, pois está mais relacionado ao o que estudar que ao como conhecemos as coisas. Trata-se de um avanço fundamental, pois é uma forma criativa de redefinir o objeto de estudo de forma dinâmica superando a fratura clássica entre estruturalistas e os acionalistas que marcou durante muito tempo o estudo dos movimentos sociais. $\mathrm{O}$ giro epistemológico permanece como um grande desafio no qual devemos avançar nos próximos anos não só para incluir estudos de novas áreas geográficas não-ocidentais, mas para incorporar também novas visões de mundo e saberes silenciados que podem contribuir muito ao entendimento das novas formas de resistência no mundo contemporâneo. Aproveito a ocasião para concluir esses comentários relembrando uma afirmação de Tilly (1995), quando acabava um de seus mais bonitos escritos sobre democracia e democratização, titulado Democracy is a Lake. Dizia Tilly: "A democracia sempre expõe o seguinte cartaz: em construção". Esse também é o cartaz que levantam na atualidade os estudos sobre as ações coletivas e os movimentos sociais: em reconstrução. 


\section{Referências}

ALONSO, A. As teorias dos movimentos sociais: um balanço do debate. Lua Nova, São Paulo, n.76, 2009.

AUYERO, J. Routine politics and violence in Argentina. The Gray zone of state Power. Cambridge: Cambridge University Press, 2007.

AYERBE, L.F. Estados Unidos e América Latina. A construção da hegemonia. São Paulo: Editora da UNESP, 2002.

BRINGEL, B. Ativismo transnacional, o estudo dos movimentos sociais e as novas geografias pós-coloniais. Estudos de Sociologia, Recife, n.16. Dossiê especial da Associação Latino-americana de Sociologia (ALAS), 2010.

BRINGEL, B. \& ECHART, E. (2010a) Dez anos de Seattle, o movimento antiglobalização e a ação coletiva transnacional. Ciências Sociais UNISINOS, v.46, n.1, p.28-36, 2010A.

. De Seattle a Copenhagen (con escala en la Amazonía): del movimiento antiglobalización al nuevo activismo transnacional". In: Pedro Ibarra e Elena Grau (Eds.) Jóvenes en la Red. Anuario de Movimientos Sociales 2010. Barcelona: Icaria Editorial, p.191-201, 2010b.

- Movimentos sociais e democracia: os dois lados das fronteiras. Caderno CRH, v.21, n.54, p. 457-475, 2008.

BRINGEL, B. \& CAIRO, H. (2010) Articulaciones del Sur global: afinidad cultural, internacionalismo solidario e Iberoamérica en la globalización contra-hegemónica. In: CAIRO, H. \& GROSFOGUEL, R. (Eds.) Descolonizar Europa descolonizar la modernidad: diálogos América Latina-Europa. Madrid: IEPALA, p.233-255, 2010.

BRUCKMAN, M. \& DOS SANTOS, T. Os movimentos sociais na América Latina: um balanço histórico. In: DOS SANTOS, T. (Coord.) Países emergentes e os novos caminhos da modernidade. Brasília: UNESCO, p. 181-202, 2008.

DOMINGUES,J.M. A América Latina e a modernidade contemporânea. Uma interpretação sociológica. Belo Horizonte: UFMG, 2009.

DUSSEL, E. Descolonización de La filosofía política ayer y hoy. In: CAIRO, H. \& GROSFOGUEL, R. (Eds.) Descolonizar la modernidad. Descolonizar Europa. Un diálogo Europa-América Latina. Madrid: IEPALA, 2010. 
ECHART, E. Movimientos sociales y relaciones internacionales. La irrupción de un nuevo actor. Madrid: IUDC-Catarata, 2008.

FALS-BORBA, O. Campesinos de los Andes: estudio sociológico de Saucío. Bogotá: Universidad Nacional, 1961.

FRANZÉ, J. ¿De qué pensamiento y de qué política se habla cuando hablamos de historia del pensamiento político?. In: CAIRO, H. \& SIERRA, G. (Comps.) América Latina, una y diversa: teorías y métodos para su análisis. San José: Alma Mater, 2008.

FREIRE, P. Educação como prática da liberdade. Rio de Janeiro: Paz e Terra, 1967.

GADEA, C. \& SCHERER-WARREN, I. A contribuição de Alain Touraine para o debate sobre sujeito e democracia latino-americanos. Revista de Sociologia e Política, Curitiba, n.25, 2005.

GARCÍA LINERA, A. El evismo: lo nacional-popular en acción. Observatorio Social de América Latina, Buenos Aires (CLACSO), n.19, 2006.

GOHN, M.G. Teorias dos movimentos sociais. Paradigmas clássicos e contemporâneos. São Paulo: Loyola, 1997.

2008.

. Novas teorias dos movimentos sociais. São Paulo: Loyola,

- Movimentos sociais e redes de mobilizações civis no Brasil contemporâneo. Petrópolis: Vozes, 2010.

GONZÁLEZ CASANOVA, P. Sociedad plural, colonialismo interno y desarrollo. América Latina. Revista del Centro Latinoamericano de Ciencias Sociales, México D.F., año VI, n.3, 1963.

KAY, C. Teorias estruturalistas e teoria da dependência na era da globalização neoliberal. In: SADER, E. \& SANTOS, T. (Coords.) A América Latina e os desafios da globalização. Ensaios dedicados a Rui Mauro Marini. São Paulo: Boitempo, 2009.

KLANDERMANS, B. \& ROGGENAND, C. (Eds.) Handbook of social movements across disciplines. New York: Springer, 2007.

MARIATEGUI, J.C. Por um socialismo indo-americano. Seleção e introdução de Michael Löwy. Rio de Janeiro: UFRJ, 2005. 
MCADAM, D.; TARROW, S. \& TILLY, C. Dynamics of contention. Cambridge: Cambridge University Press, 2001. n.76, 2009.

. Para mapear o confronto político. Lua Nova, São Paulo,

MEYER, D. \& TARROW, S. (Eds.) The social movement society. Contentious Politics for a new century. Oxford: Rowman \& Littlefield Publishers, 1998.

MIGNOLO, W. Histórias locais/Projetos globais: colonialidade, saberes subalternos e pensamento liminar. Belo Horizonte: UFMG, 2003.

PORTO-GONÇALVES, Carlos Walter Geo-grafías: movimientos sociales, nuevas territorialidades y sustentablidad. México D.F.: Siglo XXI, 2001.

SADER, E. Quando novos personagens entraram em cena. Experiências e lutas dos trabalhadores da Grande São Paulo: 1970-1980. São Paulo: Paz e Terra, 1988.

SANDOVAL, Salvador Os trabalhadores param. Greves e mudança social no Brasil: 1945-1990. São Paulo: Editora Ática, 1994.

SCHERER-WARREN, I. \& KRISCHKE, P. (Orgs.) Uma revolução no cotidiano? Os novos movimentos sociais na América do Sul. São Paulo: Brasiliense, 1987.

SLATER, D. (Org.) New social movements and the State in Latin America. Amsterdam: CEDLA, 1985.

STAVENHAGEN, R. Decolonizing applied social sciences". Human Organization, v.30, n.4, 1971.

TARROW, S. The new transnational activism. Cambridge: Cambridge University Press, 2005.

. The profession confessions of a recovering structuralist. European Political Science (ECPR), n.5, 2006.

. $\mathrm{O}$ poder em movimento. Movimentos sociais e confronto político. Petrópolis: Editora Vozes, 2009a.

. Outsiders inside e insiders outside: entre a ação pública nacional e transnacional em prol dos direitos humanos". Caderno CRH, Salvador, v.22, n.55, 2009b. 
. Dynamics of diffusion: mechanisms, institutions and scales shift. In: GIVANS, R. ROBERTS, K. \& SOULE, S. (Eds.) The diffusion of social movements: actors, mechanisms and political effects. Cambridge: Cambridge University Press (no prelo), 2010.

. Power in Movement. Social Movements and Contentious

Politics. 3a edição revisada. Cambridge: Cambridge University Press (no prelo), 2011.

TILLY, C. From mobilization to revolution. New York: McGraw-Hill, 1978.

. Democracy is a lake. In: ANDREWS, G. \& CHAPMAN, H. (Eds.) The social construction of democracy. New York: New York University Press, 1995.

Press, 2008.

. Contentious performances. Cambridge: Cambridge University . Movimentos sociais como política. Revista Brasileira de Ciência Política, Brasília, n.3, 2010.

TOURAINE, A. Los problemas de una sociología propia en América Latina. Revista Mexicana de Sociología, México D.F., v.51, n.3, 1989a.

. Palavra e sangue. Política e sociedade na América Latina. Campinas: Editora da UNICAMP, 1989b.

VON BÜLOW, M. Building transnational networks. Civil society and the politics of trade in the Americas. Cambridge: Cambridge University Press, 2010.

YASHAR, D. Contesting citizenship in Latin America. The rise of indigenous movements and the postliberal challenge. Cambridge: Cambridge University Press, 2005.

ZIBECHI, R. Dispersar el poder. Los movimientos sociales como poderes antiestatales. Buenos Aires: Tinta Limón, 2006.

. Autonomías y emancipaciones. América Latina en movimiento. Lima: Programa Democracia y Transformación Global / Editorial UNMSM, 2007. 
